\title{
Long term safety of methotrexate in routine clinical care: discontinuation is unusual and rarely the result of laboratory abnormalities
}

\author{
Y Yazici, T Sokka, H Kautiainen, C Swearingen, I Kulman, T Pincus
}

See end of article for authors' affiliations

Correspondence to: Dr Yusuf Yazici, 515 East 72nd Street \#29E, New York, NY 10021, USA; yaziciy@yahoo.com

Accepted 9 May 2004 Published Online First 18 June 2004

\begin{abstract}
Objective: To analyse patients with rheumatoid arthritis, treated with methotrexate in a weekly academic rheumatology clinic over 13 years, for continuation of courses and reasons for discontinuation. Methods: All 248 patients with an analysable longitudinal course who took methotrexate in standard care between 1990 and 2003 were studied. Continuation of courses was analysed using life tables. All abnormal and severely abnormal values for aspartate aminotransferase (AST) $>40 \mathrm{U} / \mathrm{l},>80 \mathrm{U} / \mathrm{l}$, albumin $<35 \mathrm{~g} / \mathrm{l},<30 \mathrm{~g} / \mathrm{l}$, white blood cell (WBC) count $<4.0 \times 10^{9} / \mathrm{l},<3.0 \times 10^{9} / \mathrm{l}$, and platelet count $<150 \times 10^{9} / \mathrm{l},<100 \times 10^{9} /$, were identified. Responses of the clinician and subsequent laboratory values were reviewed.

Results: Over 1007 person-years, the probability of continuing methotrexate over five years was 79\% (95\% confidence interval, $72 \%$ to $84 \%$ ). Severe laboratory abnormalities occurred in 2.9 per 100 personyears, specifically 0.9 for AST $>80 \mathrm{U} / \mathrm{l}, 1.1$ for albumin $<30 \mathrm{~g} / \mathrm{l}, 0.7$ for $\mathrm{WBC}<3.0 \times 10^{9} / \mathrm{l}$, and 0.3 for platelets $<100 \times 10^{9} /$. No severe laboratory abnormality progressed to further severity or clinical disease. Permanent discontinuations of methotrexate occurred in 46 patients (19\%), 26 (10\% of all patients) for adverse effects, 15 (32.6\%) for inefficacy; only two discontinuations resulted from laboratory abnormalities, both of WBC, possibly from other sources.

Conclusions: Methotrexate was associated with a high rate of continuation, and few clinically significant laboratory abnormalities. Discontinuation primarily reflected clinical rather than laboratory findings. Vigilance for methotrexate toxicity is required but methotrexate appears among the safest treatments for rheumatoid arthritis.
\end{abstract}

\section{METHODS}

A database to monitor all consecutive patients seen at a weekly academic clinic has been maintained since the 1980s by TP. It has been the policy since 1990 to consider all patients with rheumatoid arthritis as candidates for methotrexate, generally beginning this treatment at the first or second visit. Patients who are treated with methotrexate in this clinic are advised to limit alcohol intake to two drinks a day, but not necessarily to abstain totally.

The database included 418 patients who were seen between 1990 and 2003 and met the 1987 revised American College of Rheumatology (ACR) criteria for rheumatoid arthritis. ${ }^{15}$ Among these patients, 93 had no therapeutic decisions by TP, including 27 seen by TP before 1990 but by other rheumatologists after 1990, 19 patients of other rheumatologists seen only once by TP for a "second opinion," and 47 seen only for a research protocol. Most of these patients took methotrexate at some time. Another 48 had methotrexate prescribed but no laboratory data were available during the study period, including 21 who never returned for another visit, eight who refused to take methotrexate, seven who had methotrexate prescribed by a previous physician and discontinued because of toxicity before being seen by TP, four who had clinical toxicity after one dose and did not continue methotrexate, and eight who had no follow up laboratory tests within the study periodthat is, methotrexate began in 2003. Among the remaining 277 patients, 29 were not prescribed methotrexate, including 18 judged to have sufficiently controlled disease, five with severe comorbidities, two who were regarded as too debilitated for methotrexate, three who had more than three alcoholic drinks a day regularly, and one who was pregnant.

Abbreviations: ACR, American College of Rheumatology; DMARD, disease modifying antirheumatic drug; NSAID, non-steroidal antiinflammatory drug 
Altogether, 248 of 277 patients (89.5\%) who were eligible for methotrexate treatment received methotrexate (or 296 of 325 $(91.1 \%)$, including those who had methotrexate prescribed but were not recruited to the study because no laboratory data were available during the study period). The study database included the 248 patients who met ACR criteria and who had been treated with methotrexate by TP in standard non-protocol clinical care.

Continuation of methotrexate courses was calculated using life table analyses and Kaplan-Meier statistics. The reasons for discontinuation were recorded and compiled using descriptive statistics. Twenty seven patients had started methotrexate before January 1990 and their courses were included in the survival analyses only.

The database was examined for laboratory abnormalities from 1 January 1990 or the date of institution of methotrexate, whichever occurred later, to the first occurrence of any abnormalities or discontinuation of the observation period, whichever came first.

Abnormal laboratory results were defined as follows:

- aspartate aminotransferase (AST) $>40 \mathrm{U} / \mathrm{l}$;

- albumin <35 g/l;

- white blood count (WBC) $<4.0 \times 10^{9} / 1$;

- platelets $<150 \times 10^{9} / 1$.

Clinically severe abnormal results were defined as AST $>80 \mathrm{U} / \mathrm{l}$, albumin $<30 \mathrm{~g} / \mathrm{l}, \mathrm{WBC}<3.0 \times 10^{9} / \mathrm{l}$, and platelets $<100 \times 10^{9} /$. The number of patients with incident abnormal results and person-years at risk were calculated over the observation period. All patients with severely abnormal laboratory tests were reviewed for further tests and clinical outcomes. The actions of the clinician taken in response to all abnormalities of AST, albumin, WBC, and platelets, and subsequent laboratory test results, were recorded from the medical record and database.

\section{RESULTS}

Among all 248 study patients with rheumatoid arthritis who had taken methotrexate in standard care between 1990 and 2003, 182 (73\%) were female and 230 (93\%) were white; the mean age was 55 years and median duration of disease 5.8 years. The mean (SD) frequency of laboratory tests was every 15 (19) weeks with a median of 13 weeks; most patients had laboratory evaluations every three to four months. The mean (median) dose of methotrexate was 9.0 (7.5) $\mathrm{mg}$ at the first visit during the study period and $12.6(10.0) \mathrm{mg}$ at the last

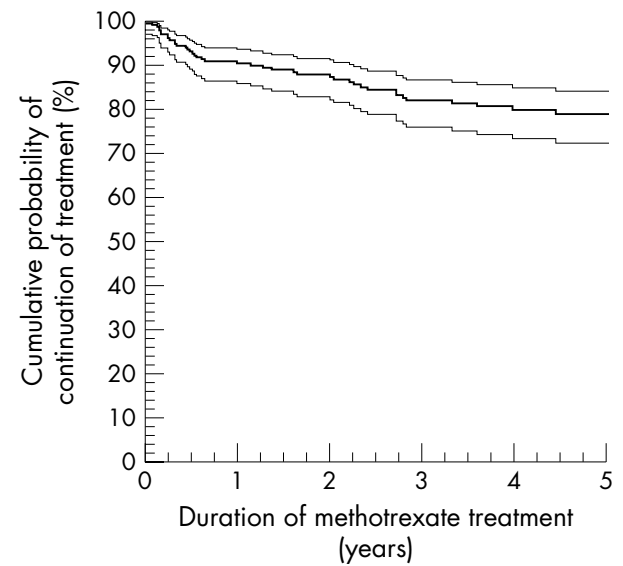

Figure 1 Cumulative probability (with 95\% confidence interval) for continuation of methotrexate treatment in 248 patients with rheumatoid arthritis.

visit. Prednisone was taken by 213 patients (86\%) with a mean (median) dose of 5.6 (5.0) $\mathrm{mg}$ at the first visit during the study period, and $218(88 \%)$ patients were taking prednisone of $5.2(5.0) \mathrm{mg}$ at the last visit. Folic acid was taken by 228 patients (92\%). Hydroxychloroquine was taken by 84 patients $(34 \%)$ concomitantly with methotrexate at least some of the time.

The cumulative probability of the 248 patients continuing to take methotrexate after five years was $79 \% \quad(95 \%$ confidence interval (CI), $72 \%$ to $84 \%$ ) (fig 1). Overall, 46 patients $(18.5 \%)$ discontinued methotrexate and did not restart it during the observation period. The reasons for discontinuation included adverse effects in 26 patients (56.5\% of discontinuations), inefficacy in 15 (32.6\%), improvement of status in three $(6.5 \%)$, pregnancy in one $(2.1 \%)$, and other disease (lung cancer) in one $(2.1 \%)$ (table 1). Of the 26 patients who discontinued because of adverse effects, six were for gastrointestinal toxicity, three for oral ulcers, three for rash, three for malaise, three for pulmonary symptoms, two for pneumonia, two for nodules, two for other side effects, and two for laboratory data (neither of which was found in routine testing).

In a follow up of 1007 person-years (mean 4.1 years, median 3.1 years per patient), the incidence of any abnormal laboratory test (table 2) was 20 (95\% CI, 16 to 24 ) per 100

\begin{tabular}{|c|c|c|c|}
\hline Reason for discontinuation & $\begin{array}{l}\text { Discontinued } \\
\text { methotrexate } \\
\text { permanently (n) }\end{array}$ & $\begin{array}{l}\text { Per cent of } \\
\text { discontinuations } \\
(n=46)\end{array}$ & $\begin{array}{l}\text { Per cent of all } \\
\text { patients }(n=248)\end{array}$ \\
\hline Adverse effects & 26 & $56.5 \%$ & $10.4 \%$ \\
\hline Gastrointestinal & 6 & $13.0 \%$ & $2.4 \%$ \\
\hline Oral ulcers & 3 & $6.5 \%$ & $1.2 \%$ \\
\hline Skin rash & 3 & $6.5 \%$ & $1.2 \%$ \\
\hline Malaise & 3 & $6.5 \%$ & $1.2 \%$ \\
\hline Pulmonary symptoms & 3 & $6.5 \%$ & $1.2 \%$ \\
\hline Pneumonia & 2 & $4.3 \%$ & $0.8 \%$ \\
\hline Nodules & 2 & $4.3 \%$ & $0.8 \%$ \\
\hline Laboratory abnormalities & 2 & $4.3 \%$ & $0.8 \%$ \\
\hline Other side effects & 2 & $4.3 \%$ & $0.8 \%$ \\
\hline Inefficacy & 15 & $32.6 \%$ & $6.0 \%$ \\
\hline Other reasons & 5 & $10.9 \%$ & $2.0 \%$ \\
\hline Disease improved & 3 & $6.5 \%$ & $1.2 \%$ \\
\hline Other diseases & 1 & $2.2 \%$ & $0.4 \%$ \\
\hline Pregnancy & 1 & $2.2 \%$ & $0.4 \%$ \\
\hline
\end{tabular}




\begin{tabular}{|c|c|c|c|}
\hline Abnormality & $\mathbf{n}$ & $\begin{array}{l}\text { Person-years } \\
\text { at risk }\end{array}$ & $\begin{array}{l}\text { Incidence per } 100 \text { person-years } \\
(95 \% \mathrm{Cl})^{*}\end{array}$ \\
\hline AST $>40 \mathrm{U} / \mathrm{I}$ & 56 & 792 & 7.1 (5.3 to 9.2$)$ \\
\hline Albumin $<35 \mathrm{~g} / \mathrm{l}$ & 68 & 784 & $8.7(6.7$ to 11.0$)$ \\
\hline WBC $<4.0 \times 10^{9} / 1$ & 18 & 927 & $1.9(1.1$ to 3.1$)$ \\
\hline Platelets $<150 \times 10^{9} / 1$ & 17 & 945 & $1.8(1.0$ to 2.9$)$ \\
\hline Any abnormality & 111 & 560 & 20 (16 to 24$)$ \\
\hline \multicolumn{4}{|l|}{ Clinically severe abnormalities } \\
\hline AST $>80 \mathrm{U} / \mathrm{l}$ & 9 & 980 & $0.9(0.4$ to 1.7$)$ \\
\hline Albumin $<30 \mathrm{~g} / \mathrm{l}$ & 11 & 990 & $1.1(0.6$ to 2.0$)$ \\
\hline$W B C<3.0 \times 10^{9} / 1$ & 7 & 988 & $0.7(0.3$ to 1.5$)$ \\
\hline Platelets $<100 \times 10^{9} / 1$ & 3 & 990 & $0.3(0.1$ to 0.9$)$ \\
\hline Any clinically severe abnormality & 27 & 930 & $2.9(1.9$ to 4.2$)$ \\
\hline
\end{tabular}

person-years; specifically, 7.1 for AST $>40 \mathrm{U} / \mathrm{l}, 8.7$ for albumin $<35 \mathrm{~g} / \mathrm{l}, 1.9$ for $\mathrm{WBC}<4.0 \times 10^{9} / \mathrm{l}$, and 1.8 for platelets $<150 \times 10^{9} / 1$. The incidence of any clinically severe abnormality was 2.9 (95\% CI, 1.9 to 4.2 ) per 100 person-years (table 2); specifically, 0.9 for AST $>80 \mathrm{U} / \mathrm{l}, 1.1$ for albumin $<30 \mathrm{~g} / \mathrm{l}, 0.7$ for $\mathrm{WBC}<3.0 \times 10^{9} / \mathrm{l}$, and 0.3 for platelets $<100 \times 10^{9} / 1$. The likelihood of a clinically severe laboratory abnormality appeared similar during each year over the five years of observation.

In most situations, no action was taken by the clinician in response to the abnormalities (table 3). In one patient, methotrexate was discontinued for seven months because of an AST value of $149 \mathrm{I} / \mathrm{U}$ but was then reinstated at the patient's request; AST values remained mildly elevated. The median (range) follow up period after clinically important abnormalities was $2.6(0.7$ to 10.5$)$ years for the nine patients with AST $>80 \mathrm{U} / \mathrm{I}, 2.4$ (0.2 to 4.1$)$ years for the 11 patients with albumin $<30 \mathrm{~g} / \mathrm{l}, 2.1$ (1.0 to 4.9 ) years for the seven patients with $\mathrm{WBC}<3.0 \times 10^{9} / 1$, and $10.9,4.3$, and 2.5 years for the three patients with platelets $<100 \times 10^{9} / 1$ (table 3 ).

During the follow up period, all patients with severely abnormal values had values in the normal or near normal range, with one exception-a patient with Felty's syndrome who had been under care for only 1.1 years at the time the data were analysed. All severely abnormal values were followed by a value in the normal or mildly abnormal range, and no abnormal laboratory value developed into a serious clinical problem, including cirrhosis or death. No patient had a liver biopsy.

Two patients discontinued methotrexate because of apparent laboratory abnormalities. A 77 year old man developed diarrhoea and weakness after beginning treatment with a new NSAID, having taken methotrexate for six years. His WBC was $0.7 \times 10^{9} / 1$ when he was admitted to a hospital. WBC was normal at discharge, but methotrexate was nonetheless discontinued. A 43 year old man reported that he was told by his primary care physician to discontinue methotrexate because of a low WBC. His WBC was never recorded as abnormal in regular clinic laboratory testing. Nonetheless, the patient elected to discontinue methotrexate. Neither of these WBC abnormalities leading to discontinuation was found in regular laboratory safety monitoring. No patient discontinued methotrexate permanently because of abnormalities of AST, albumin, or platelets.

\section{DISCUSSION}

Over 1007 person-years of methotrexate, the incidence of any laboratory abnormality was 20 per 100 person-years at risk, the incidence of clinically severe laboratory abnormalities was 2.9 per 100 person-years, and the incidence of a clinically severely abnormal AST value was 0.9 per 100 person-years. Severe laboratory abnormalities were unusual, and no patient with laboratory abnormalities showed increased clinical or laboratory severity over time. All patients with abnormalities had a laboratory test within a normal or near normal range on subsequent testing, generally without discontinuing methotrexate, and in most cases without changing the dose, except for one patient who had Felty's syndrome.

It is the policy of this clinic to consider methotrexate for all patients with rheumatoid arthritis, generally on the first or second visit. Overall, 248 of 277 eligible patients (89.5\%) received methotrexate, as well as most of 141 patients excluded from the study cohort because laboratory data were not available for methotrexate or they were included in research protocols (see Methods). No severely abnormal laboratory values were noted in the excluded patients, although there was not a rigorous search for all laboratory tests as in the study patients. In the 248 study patients, methotrexate was discontinued without restart in only two patients because of abnormal laboratory results, neither of which was identified on routine safety tests. A low WBC of 0.7 in one patient may have been caused by infection, an NSAID, or another drug, rather than by methotrexate. In the other patient, the WBC was low only once, and it was questionable whether this was caused by methotrexate. No AST or albumin values in regular safety tests led to permanent discontinuation of methotrexate. More than $90 \%$ of the adverse effect related permanent discontinuations were on the basis of a clinical problem such as gastrointestinal distress, oral ulcers, and so on, rather than a laboratory abnormality. Therefore, clinical monitoring of methotrexate for toxicity appears at least as important as laboratory monitoring.

The results presented here are similar to those in a previous prospective long term observational study of 271 patients over a mean treatment duration of 31.4 months with a mean methotrexate dose of $17 \mathrm{mg}$, in whom leucopenia $<4.0 \times 10^{9} / 1$ occurred in only eight patients $(3 \%)$ and thrombocytopenia $<100 \times 10^{9} / 1$ in only seven $(2.5 \%){ }^{6}$ However, any AST elevation was encountered in $17 \%$ of patients, any serum alanine transaminase (ALT) elevation in 34\%, and severe ALT elevation in $6 \%$, perhaps because folate supplementation was not used. ${ }^{6}$ Nonetheless, severe disturbance of hepatic function tests was rare in that study, and the number of withdrawals (16.5\%) is comparable with the discontinuation rate seen in the present study. Furthermore, no withdrawals occurred because of a laboratory abnormality encountered in patient monitoring. ${ }^{6}$ 
Table 3 Severely abnormal laboratory abnormalities among 248 patients with rheumatoid arthritis treated with methotrexate

\begin{tabular}{|c|c|c|c|c|c|}
\hline \multirow[b]{2}{*}{ Patient } & \multirow[b]{2}{*}{$\begin{array}{l}\text { Severely abnormal } \\
\text { value }\end{array}$} & \multirow[b]{2}{*}{ Clinical action taken } & \multicolumn{3}{|c|}{ Subsequent tests after severe abnormal values } \\
\hline & & & $\begin{array}{l}\text { Duration of follow up } \\
\text { (years) }\end{array}$ & Number of tests & $\begin{array}{l}\text { Median value (min, } \\
\text { max) }\end{array}$ \\
\hline & AST & & & & \\
\hline 1 & 234 & MTX 7.5 to $12.5 \mathrm{mg}$ & 0.7 & 1 & 12 \\
\hline 2 & 198 & MTX 22.5 to $15.0 \mathrm{mg}$ & 2.4 & 5 & $50(15,83)$ \\
\hline 3 & 161 & None & 10.5 & 22 & $35(25,128)$ \\
\hline 4 & 149 & MTX stopped for 7 months & 3.1 & 16 & $32(23,91)$ \\
\hline 5 & 134 & MTX 7.5 to $12.5 \mathrm{mg}$ & 6.5 & 28 & $23(14,41)$ \\
\hline 6 & 131 & None & 4.6 & 15 & $60(24,141)$ \\
\hline 7 & 124 & None & 2.6 & 8 & $56(44,96)$ \\
\hline 8 & 115 & MTX 22.5 to $10 \mathrm{mg}$ & 1.1 & 4 & $16(14,22)$ \\
\hline \multirow[t]{2}{*}{9} & 108 & None & 1.6 & 6 & $22(20,41)$ \\
\hline & Albumin & & & & \\
\hline 10 & 28 & MTX resumed $7.5 \mathrm{mg}$ & 3.2 & 9 & $34(32,37)$ \\
\hline 11 & 28 & MTX 7.5 to $15 \mathrm{mg}$ & 1.6 & 6 & $30(25,32)$ \\
\hline 12 & 27 & Internist informed of abnormalities & 4.1 & 14 & $34(26,41)$ \\
\hline 13 & 29 & MTX 15 to $7.5 \mathrm{mg}$ & 2.5 & 6 & $32(29,37)$ \\
\hline 14 & 29 & None & 0.7 & 3 & $33(32,33)$ \\
\hline \multirow[t]{2}{*}{15} & 28 & Patient informed of value and instructed to recheck & k 0.2 & 3 & \\
\hline & & locally & & & $31(29,31)$ \\
\hline 16 & 29 & None & 2.7 & 6 & $32(30,37)$ \\
\hline 17 & 29 & None & 2.4 & 4 & $30(29,30)$ \\
\hline 18 & 29 & None & 0.6 & 2 & $37(36,38)$ \\
\hline 19 & 28 & None & 3.5 & 10 & $36(31,42)$ \\
\hline \multirow[t]{2}{*}{20} & 27 & Abnormality noted in chart & 2.3 & 7 & $32(26,35)$ \\
\hline & WBC & & & & \\
\hline 21 & 2.6 & None & 4.5 & 12 & $4.4(3.1,5.8)$ \\
\hline 22 & 2.6 & MTX 22.5 to $15 \mathrm{mg}$ & 1.0 & 3 & $4.6(4.0,4.7)$ \\
\hline 15 & 2.8 & $\begin{array}{l}\text { Patient informed of value and instructed to recheck } \\
\text { locally }\end{array}$ & k 0.2 & 3 & $7.6(6.0,10.6)$ \\
\hline 23 & 2.9 & None & 4.9 & 13 & $4.2(3.5,8.9)$ \\
\hline 24 & 1.9 & MTX 10 to $15 \mathrm{mg}$ & 1.1 & 5 & $2.4(2.2,2.8)$ \\
\hline 25 & 2.2 & None & 5.4 & 17 & $5.0(3.2,8.9)$ \\
\hline \multirow[t]{2}{*}{26} & 1.6 & MTX withheld for one week & 2.1 & 14 & $6.2(3.8,9.1)$ \\
\hline & Platelet count & & & & \\
\hline 10 & 87 & MTX 7.5 to $15 \mathrm{mg}$ & 2.5 & 7 & $109(104,136)$ \\
\hline 27 & 80 & None & 10.9 & 35 & $107(75,154)$ \\
\hline 4 & 84 & None & 4.3 & 16 & $87(62,118)$ \\
\hline
\end{tabular}

The results are also consistent with experience at the Hospital for Special Surgery, ${ }^{10}$ which indicated $94(3.4 \%)$ abnormal liver function tests in 2791 tests carried out in 182 patients with rheumatoid arthritis. In that study, the most common reason for discontinuation of methotrexate was inadequate clinical response rather than side effects, and few clinically significant adverse effects were seen. The frequent use of folic acid supplementation may have contributed to these results.

This report also confirms findings more than a decade ago that at least $50 \%$ of courses of methotrexate were continued over five years, compared with fewer than $20 \%$ of courses of traditional DMARDs, ${ }^{16}{ }^{17}$ with even higher continuation rates at this time, possibly reflecting the earlier use of methotrexate over the years. The $0.9 \%$ incidences of twice normal AST abnormalities per 100 patient-years taking methotrexate found in this study is in the range of, or even lower than, listed for rofecoxib, celecoxib, and other NSAIDs $(2-3 \%$ in the package insert for these drugs). ${ }^{18}$

No liver biopsies were done, as several studies have suggested that hepatic fibrosis seen in early studies may have been related to rheumatoid arthritis and other drugs rather than to methotrexate, were not clinically significant, and rarely progressed to cirrhosis. ${ }^{19-22}$ It has been suggested that routine liver biopsy during methotrexate treatment exposes the patient to greater risk than clinically relevant information would justify and is not cost-effective, ${ }^{21-23}$ a viewpoint which influenced the approach to the patients under care in our study. In a study of patients with psoriasis who were diagnosed with cirrhosis but chose to continue methotrexate therapy, most showed a similar grade or even improvement in the cirrhosis upon repeat biopsy. ${ }^{24}$

There are several limitations to this study. First, there was no prospective systematic analysis of specific clinical toxicities of methotrexate at each visit, so that some patients may have had toxicities such as oral ulcers not recorded here. However, all abnormal laboratory tests, as well as discontinuations and their basis, were recorded. Second, there was no specific recording of the alcohol intake of the patients, although it is known that some of these patients did consume two alcoholic drinks a day. Third, although the patients were observed over a 13 year period, the data were obtained in a once a week clinic. However, the clinic functions as a regular clinical setting on that day, and longitudinal data have been recorded over many years in many patients. Fourth, 1007 patient-years are insufficient to exclude a rare abnormality; however, similar data were reported for more than 18000 patients at the most recent meeting of the American College of Rheumatology. 25

We conclude that weekly low dose methotrexate appears to have toxicity in the range of NSAID or cyclo-oxygenase-2selective drugs, unlike high dose methotrexate given as a cytotoxic chemotherapeutic agent in the treatment of neoplasia. ${ }^{14}$ The "side effects" of rheumatoid arthritis in its natural history ${ }^{26}{ }^{27}$ appear substantially greater than the side effects of methotrexate documented in this and other reports 
over long periods, particularly with emerging data that methotrexate treatment appears to be associated with improved survival. ${ }^{78}$ Of course, vigilance for clinical and laboratory toxicities is required in the use of methotrexate or any other drug, particularly in patients who have compromised hepatic or renal function. ${ }^{28}$ Nonetheless, these observations may suggest some shift in physician attitudes as well as in clinical and pharmacy approaches to the use of weekly low dose methotrexate in patients with rheumatoid arthritis.

\section{ACKNOWLEDGEMENTS}

Supported in part by grants from Centocor and by NIH Grant HL 67964.

\section{Authors' affiliations}

Y Yazici, Brooklyn Heights Arthritis Associates, Long Island College Hospital, Brooklyn, New York, USA

T Sokka, Vanderbilt University, Nashville, Tennessee, and Jyväskylä Central Hospital, Jyväskylä, Finland

H Kautiainen, Rheumatism Foundation Hospital, Heinola, Finland

C Swearingen, T Pincus, Vanderbilt University, Nashville, Tennessee

I Kulman, Mount Sinai School of Medicine, New York

\section{REFERENCES}

1 Sokka T, Pincus T. Contemporary disease modifying antirheumatic drugs (DMARD) in patients with recent onset rheumatoid arthritis in a US private practice: methotrexate as the anchor drug in $90 \%$ and new DMARD in $30 \%$ of patients. J Rheumatol 2002;29:2521-4.

2 Hanrahan PS, Scrivens GA, Russell AS. Prospective long term followup of methotrexate therapy in rheumatoid arthritis: toxicity, efficacy and radiological progression. Br J Rheumatol 1989;28:147-53.

3 Sany J, Anaya JM, Lussiez V, Couret M, Combe B, Daures JP. Treatment of rheumatoid arthritis with methotrexate: a prospective open longterm study of 191 cases. J Rheumatol 1991;18:1323-7.

4 Mielants H, Veys EM, Van Der Straeten C, Ackerman C, Goemaere S. The efficacy and toxicity of a constant low dose of methotrexate as a treatment for intractable rheumatoid arthritis: An open prospective study. J Rheumatol 1991; 18:978-83.

5 Alarcon GS, Tracy IC, Strand GM, Singh K, Macaluso M. Survival and drug discontinuation analyses in a large cohort of methotrexate treated rheumatoid arthritis patients. Ann Rheum Dis 1995;54:708-12.

6 Rau R, Schleusser B, Herborn G, Karger T. Longterm treatment of destructive rheumatoid arthritis with methotrexate. J Rheumatol 1997;24:1881-9.

7 Krause D, Schleusser B, Herborn G, Rau R. Response to methotrexate treatment is associated with reduced mortality in patients with severe rheumatoid arthritis. Arthritis Rheum 2000;43:14-21.

8 Choi HK, Hernán MA, Seeger JD, Robins JM, Wolfe F. Methotrexate and mortality in patients with rheumatoid arthritis: a prospective study. Lancet 2002;359:1173-7.
9 Pincus T, Marcum SB, Callahan LF, Adams RF, Barber J, Barth WF, et al. Longterm drug therapy for rheumatoid arthritis in seven rheumatology private practices. I. Nonsteroidal anti-inflammatory drugs. J Rheumatol 1992; 19:1874-84.

10 Yazici Y, Erkan D, Paget SA. Monitoring methotrexate hepatic toxicity in rheumatoid arthritis: is it time to update the guidelines? J Rheumatol 2002;29:1586-9.

11 Morgan SL, Baggott JE, Vaughn WH, Austin JS, Veitch TA, Lee JY, et al. Supplementation with folic acid during methotrexate therapy for rheumatoid arthritis. Ann Intern Med 1994;121:833-41.

12 Yazici Y, Erkan D, Paget SA. Monitoring by rheumatologists for methotrexate, etanercept-, infliximab-, and anakinra-associated adverse events. Arthritis Rheum 2003;48:2769-72.

13 Farber S, Diamond LK, Mercer RD, Sylvester RF, Wolf VA. Temporary remission in acute leukemia in children produced by folic acid antagonist 4amethopteroylglutamicacid (aminopterin). N Engl J Med 1948:787-93.

14 Chan ESL, Cronstein BN. Molecular action of methotrexate in inflammatory diseases. Arthritis Res 2002;4:266-73.

15 Arnett FC, Edworthy SM, Bloch DA, McShane DJ, Fries JF, Cooper NS, et al. The American Rheumatism Association 1987 revised criteria for the classification of rheumatoid arthritis. Arthritis Rheum 1988;31:315-24.

16 Wolfe F, Hawley DJ, Cathey MA. Termination of slow acting anti-rheumatic therapy in rheumatoid arthritis: A 14-year prospective evaluation of 1017 consecutive starts. J Rheumatol 1990;17:994-1002.

17 Pincus T, Marcum SB, Callahan LF. Long-term drug therapy for rheumatoid arthritis in seven rheumatology private practices. II. Second-line drugs and prednisone. J Rheumatol 1992; 19:1885-94.

18 Physicians' Desk Reference. Montvale, NJ: Thomson PDR 2003.

19 Bridges SL, Alarcon GS, Koopman WJ. Methotrexate-induced liver abnormalities in rheumatoid arthritis. J Rheumatol 1989;16:1180-3.

20 Shergy WJ, Polisson RP, Caldwell DS, Rice JR, Pisetsky DS, Allen NB. Methotrexate-associated hepatotoxicity: retrospective analysis of 210 patients with rheumatoid arthritis. Am J Med 1988;85:771-4.

21 Rau R, Karger T, Herborn G, Frenzel H. Liver biopsy findings in patients with rheumatoid arthritis undergoing longterm treatment with methotrexate. J Rheumatol 1989;16:489-93.

22 Kremer JM, Lee RG, Tolman KG. Liver histology in rheumatoid arthritis patients receiving long-term methotrexate therapy: a prospective study with baseline and sequential biopsy samples. Arthritis Rheum 1989;32:121-7.

23 Bergquist SR, Felson DT, Prashker MJ, Freedberg KA. The cost-effectiveness of liver biopsy in rheumatoid arthritis patients treated with methotrexate. Arthritis Rheum 1995;38:326-33.

24 Zachariae H, Sogaard H. Methotrexate-induced liver cirrhosis: a follow-up. Dermatologica 1987;75:178-82.

25 Cartwright VW, Michaud K, Choi HK, Wolfe F. Methotrexate, laboratory testing and risk of serious illness: analyses in 20000 patients. Arthritis Rheum 2003;48:S428.

26 Pincus T, Callahan LF. The "side effects" of rheumatoid arthritis: joint destruction, disability and early mortality. Br J Rheumatol 1993;32(suppl. 1):28-37.

27 Pincus T, Brooks RH, Callahan LF. Prediction of long-term mortality in patients with rheumatoid arthritis according to simple questionnaire and joint count measures. Ann Intern Med 1994;120:26-34.

28 Kremer JM, Alarcon GS, Lightfoot RW, Willkens RF, Furst DE, Williams HJ, et al. Methotrexate for rheumatoid arthritis: Suggested guidelines for monitoring liver toxicity. Arthritis Rheum 1994;37:316-28. 